\title{
Role of PPase-SE in Geotrichum klebahnii, a yeast-like fungus able to solubilize pectin
}

\author{
Natalia Lorena Rojas \\ Centro de Investigación y Desarrollo en Fermentaciones Industriales \\ Facultad de Ciencias Exactas \\ Universidad Nacional de La Plata \\ Calle 47 y 115, (1900) La Plata, Argentina \\ Tel/Fax: 542214833794 \\ E-mail: rojas@biotec.org.ar \\ Sebastián Fernando Cavalitto \\ Centro de Investigación y Desarrollo en Fermentaciones Industriales \\ Facultad de Ciencias Exactas \\ Universidad Nacional de La Plata \\ Calle 47 y 115, (1900) La Plata, Argentina \\ Tel/Fax: 542214833794 \\ E-mail: cavali@biotec.org.ar

\section{Carlos Fernando Mignone} \\ Centro de Investigación y Desarrollo en Fermentaciones Industriales \\ Facultad de Ciencias Exactas \\ Universidad Nacional de La Plata \\ Calle 47 y 115, (1900) La Plata, Argentina \\ Tel/Fax: 542214833794 \\ E-mail: mignone@biotec.org.ar

\section{Roque Alberto Hours*} \\ Centro de Investigación y Desarrollo en Fermentaciones Industriales \\ Facultad de Ciencias Exactas \\ Universidad Nacional de La Plata \\ Calle 47 y 115, (1900) La Plata, Argentina \\ Tel/Fax: 542214833794 \\ E-mail: hours@biotec.org.ar \\ Website: http://www.cindefi.org.ar
}

Financial support: This work was supported by Grants for Scientific Research from La Plata National University (11/X304) and the Argentine National Agency for the Promotion of Science and Technology (PICT99 \# 14-07288).

Keywords: carbon balance, enzymatic pectin extraction, microbial pectin utilization, pectinases, synthetic medium.

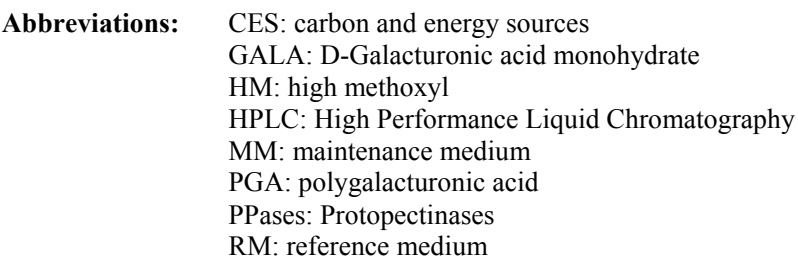

Abbreviations: CES: carbon and energy sources

GALA: D-Galacturonic acid monohydrate

HM: high methoxyl

HPLC: High Performance Liquid Chromatography

MM: maintenance medium

PGA: polygalacturonic acid

PPases: Protopectinases

RM: reference medium

Protopectinases (PPases) constitute a heterogeneous group of extracellular enzymes able to release soluble pectin from insoluble protopectin in plant tissues. Geotrichum klebahnii (ATCC 42397) produces PPaseSE with endopolygalacturonase activity. PPase-SE has been used for pectin extraction and maceration of plant tissues. Here, the capacity of G. klebahnii to use different pectins as carbon and energy sources (CES) was studied, in addition to PPase-SE capacity to release pectin from lemon peel. The strain was unable to use pectin from different origins as CES. When G. klebahnii was cultivated with mixtures of different amounts of glucose and citrus pectin as CES, the biomass obtained was proportional to the initial concentration of glucose,

*Corresponding author 
which was completely consumed. In addition, it produced PPase-SE in a glucose-containing medium. A culture was used for the extraction of pectin from lemon peels. Pectin was enzymatically extracted simultaneously with tissue maceration, yielding $3.7 \mathrm{~g}$ of (dry) pectin per $100 \mathrm{~g}$ of (wet) lemon peel. Extracted pectin was not metabolized by the strain. It was concluded that $G$. klebahnii uses PPase-SE to macerate, invade and colonize plant tissues, thus releasing soluble sugars to be used as CES without metabolizing solubilized pectin.

Geotrichum klebahnii ATCC 42397 (previously named Trichosporon penicillatum SNO-3) is a yeast-like fungus originally isolated from mandarin peel. It produces PPaseSE, an endopolygalacturonase (endo-PGase, EC 3.2.1.15) with pectin releasing (protopectinase, PPase) activity. The name PPase for this type of enzyme was kept to differentiate it from classical polygalacturonases without pectin releasing activity. In this way, PPases constitute a heterogeneous group of enzymes that cause the enzymatic solubilization of pectin from protopectin, the waterinsoluble parental pectic substance present in plant tissues. PPase-SE is highly efficient for the enzymatic extraction of pectin from citrus peel (Sakai and Okushima, 1980) and for maceration of potato tissues to obtain single-cell foods (Nakamura et al. 1995). Effects of culture conditions and medium composition on PPase-SE production have been published previously (Cavalitto et al. 2000; Ferreyra et al. 2002; Cavalitto and Mignone, 2007). This strain assimilates and grows on different monosaccharides (glucose, fructose, galactose and xylose) used as carbon and energy source (CES), yielding high levels of PPase-SE. In contrast, it is unable to assimilate disaccharides (maltose, sucrose, lactose). The strain can also grow on D-galacturonic acid, but biomass levels were around $50 \%$ of those achieved when glucose was used as CES. It is remarkable that PPase$\mathrm{SE}$ expression is strongly repressed by D-galacturonic acid.

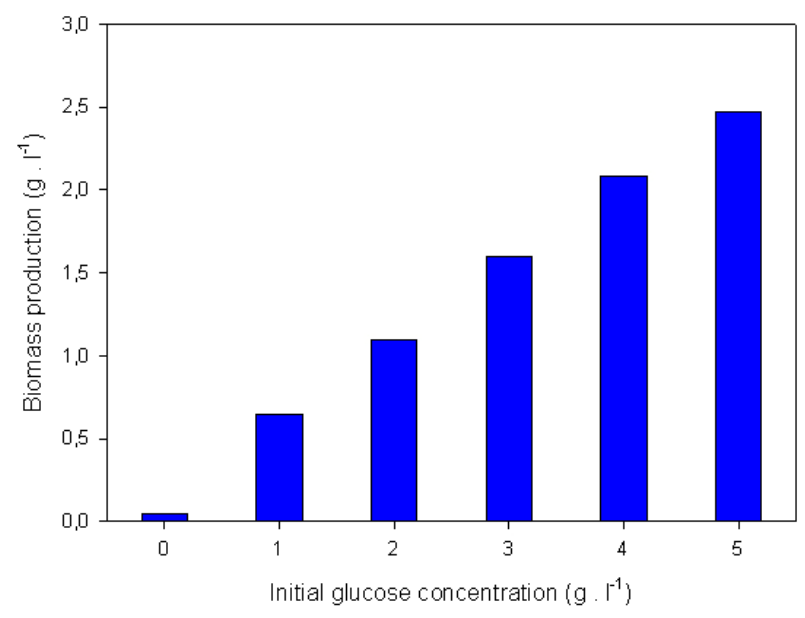

Figure 1. Biomass production in Erlenmeyer flask using RM with glucose and pectin in different proportions as CES. Total amount of CES was constant.
This phenomenon is opposite to the behaviour of several yeast strains such as $S$. cerevisiae and $C$. albidus in which it has been described as an inducer of PGases (Blanco et al. 1999). In addition, pectin, the final product of PPase-SE activity on protopectin, is apparently not metabolized. PPase-SE is the only extracellular enzyme detected in culture supernatants of this strain, and it seems to be the only biochemical tool to provide the cell with extracellular nutrients. Furthermore, there are no reports concerning any other extracellular enzyme produced by G. klebahnii. Therefore, we decided to investigate the role of PPase-SE in G. klebahnii growth and its capacity to assimilate pectins from different origins, in addition to enzymatically extracted lemon pectin. Finally, the extraction process of pectin from lemon peel was investigated.

\section{MATERIALS AND METHODS}

\section{Chemicals}

D-Galacturonic acid monohydrate (GALA), polygalacturonic acid (PGA) from orange and citrus pectin were purchased from Sigma (St. Louis, USA). All other chemicals used were commercially available and of analytical grade.

\section{Microorganism, media, inocula and culture conditions}

G. klebahnii ATCC 42397 was used. Permanent cell stocks, in $15 \%(\mathrm{v} / \mathrm{v})$ glycerol, were stored at $-70^{\circ} \mathrm{C}$. When necessary, cells were streaked and grown in a maintenance medium (MM) with the following composition (per liter): 5 $\mathrm{g}$ meat peptone (Difco), $5 \mathrm{~g}$ yeast extract (Difco), $20 \mathrm{~g}$ glucose, and $20 \mathrm{~g}$ agar, $\mathrm{pH} 5.0$, at $30^{\circ} \mathrm{C}$, and kept at $4^{\circ} \mathrm{C}$ under a layer of mineral oil for 6 months, at most.

A reference medium (RM) developed in our laboratory was also used, and it contained (per liter): $5 \mathrm{~g}$ glucose (limiting substrate), $1 \mathrm{~g} \quad \mathrm{~K}_{2} \mathrm{HPO}_{4}, 0.1 \mathrm{~g} \quad \mathrm{CaCl}_{2} \cdot 2 \mathrm{H}_{2} \mathrm{O}, 0.6 \mathrm{~g}$ $\mathrm{MgSO}_{4} \cdot 7 \mathrm{H}_{2} \mathrm{O}, 0.6 \mathrm{~g}$ urea, $0.45 \mathrm{~g}$ citric acid, $1 \mathrm{ml}$ vitamin solution, $1 \mathrm{ml}$ micronutrient solution $\mathrm{C}$, and $1 \mathrm{ml}$ micronutrient solution $\mathrm{A}, \mathrm{pH}$ 5.0.

The vitamin solution contained (per liter): $6 \mathrm{mg}$ folic acid, $6 \mathrm{mg}$ myo-inositol, $6 \mathrm{mg}$ D-biotin, $0.8 \mathrm{~g}$ calcium pantothenate, $0.8 \mathrm{~g} p$-aminobenzoic acid, $0.8 \mathrm{~g}$ riboflavin, and $1.6 \mathrm{~g}$ pyridoxine. Mineral micronutrient solution $\mathrm{C}$ contained (per liter): $0.6 \mathrm{~g}$ citric acid, $0.15 \mathrm{~g} \mathrm{CoCl}_{2}, 3 \mathrm{~g}$ $\mathrm{MnSO}_{4} \cdot \mathrm{H}_{2} \mathrm{O}, 5 \mathrm{~g} \mathrm{ZnSO}_{4} \cdot 7 \mathrm{H}_{2} \mathrm{O}, 15 \mathrm{~g} \mathrm{FeSO}_{4} \cdot 7 \mathrm{H}_{2} \mathrm{O}$ and 0.75 g CuSO $4 \cdot 5 \mathrm{H}_{2} \mathrm{O}, \mathrm{pH}$ 1.5. Mineral micronutrient solution A contained (per liter): $0.65 \mathrm{~g} \mathrm{Na}_{2} \mathrm{MoO}_{4} \cdot 2 \mathrm{H}_{2} \mathrm{O}, 0.1 \mathrm{~g} \mathrm{KI}$, and $0.1 \mathrm{~g} \mathrm{H}_{3} \mathrm{BO}_{3}$, $\mathrm{pH} 1.5$.

In some experiments, glucose in the RM was replaced by different CES: lime (Citrus aurantifolia L.) pectin, high methoxyl (HM) lime pectin, citrus pectin (Sigma), sugar beet pectin, kaki (Japanese persimmon, Diospyros kaki L.) pectin, lemon pectin (enzymaticaly extracted with PPase$\mathrm{SE}$ ), apple pectin, PGA, PGA hydrolyzed with PPase-SE, 
Table 1. Characterization of the growth of G. klebahnii cultivated in Erlenmeyers flasks using the RM with different CES.

\begin{tabular}{|l|c|l|c|}
\hline \multicolumn{1}{|c|}{ CES } & Cultivation time (hrs) & \multicolumn{1}{|c|}{ Microscopic observation } & Final pH \\
\hline Lime pectin & 80 & Very poor growth, short hyphae & 6.31 \\
\hline HM lime pectin & 80 & Very poor growth, unicellular forms & 6.06 \\
\hline Citrus pectin & 80 & Very poor growth, filamentous forms & 6.13 \\
\hline Sugar beet pectin & 80 & Very poor growth, short hyphae & 6.16 \\
\hline Kaki pectin & 80 & No growth & 6.06 \\
\hline Apple pectin & 80 & Poor growth, short hypahe & 6.55 \\
\hline PGA & 80 & Poor growth, short hypahe & 7.75 \\
\hline PGA (hydrolyzed) & 80 & Poor growth, short hypahe & 7.80 \\
\hline Lemon peel extract & 26 & Good growth, filamentous forms & 8.67 \\
\hline Washed lemon peel & 80 & No growth & 6.21 \\
\hline Lemon peel (fresh) & 26 & Medium growth, filamentous forms & 8.20 \\
\hline RM (control) & 26 & Good growth, filamentous forms & 8.20 \\
\hline
\end{tabular}

lemon peel (fresh), washed lemon peel and lemon peel extract solution.

Pectins from lime, sugar-beet, kaki and apple were prepared in the laboratory from the corresponding raw materials by acid extraction and precipitation with ethanol according to classical procedures for pectin extraction (Contreras Esquivel et al. 1997). HM lime pectin was prepared in the laboratory from lime pectin with the methanol $/ \mathrm{H}_{2} \mathrm{SO}_{4}$ method (Van Alebeek et al. 2000).

PGA was hydrolyzed with PPase-SE by the following process: $9.5 \mathrm{ml}$ solution of PGA $(5 \mathrm{~g} / \mathrm{l})$ were mixed with $0.5 \mathrm{ml}$ of PPase-SE solution $(2.8 \mathrm{U} / \mathrm{ml})$ and incubated for $15 \mathrm{~min}$ at $37^{\circ} \mathrm{C}$. No further increment in reducing power of the solution was observed at longer incubation times, therefore the enzymatic degradation of PGA was considered finished.

Commercial lemons (Citrus limon Burm, cv. Lisbon) were squeezed and the peel (albedo plus flavedo) was ground in a blender. This material was repeatedly washed with water until substances (soluble reducing sugars) that reacted with the Somogyi-Nelson reagents were washed off, yielding the washed lemon peel. Water from the first washing (lemon peel extract solution) was kept frozen until used.

Enzymatic maceration of lemon peel was carried out in triplicate $250-\mathrm{ml}$ Erlenmeyers flasks containing $97 \mathrm{ml}$ of sodium acetate buffer ( $0.2 \mathrm{M}, \mathrm{pH} 5.0), 6.5 \mathrm{~g}$ of fresh lemon peel (cylinders, $\Phi=5 \mathrm{~mm}$ ) and $3 \mathrm{ml}$ of PPase-SE solution $(300 \mathrm{U} / \mathrm{ml})$. Flasks were incubated at $30^{\circ} \mathrm{C}$, on a rotary shaker at $200 \mathrm{rpm}$. The whole content of the flasks was taken at different incubation times. Remaining solids were separated by centrifugation ( $20 \mathrm{~min}, 6,000 \mathrm{x} \mathrm{g}$ ) and the supernatant used for soluble sugars (glucose, fructose and sucrose) analysis. Macro and microscopic observations of the maceration process were also done.

All components of media were autoclaved $\left(121^{\circ} \mathrm{C}, 15\right.$ or 20 min for Erlenmeyer or bioreactor cultures, respectively) except in the cases of urea and vitamins, which were sterilized separately by filtration through a cellulosic filter paper $(0.22 \mu \mathrm{m}$, E02WP02500, MSI, USA).

Cultures were inoculated with an appropriate dilution of a suspension of the microorganism grown in MM. Initial $\mathrm{OD}_{620}$ was around 0.2 in both flasks and bioreactor cultures. 


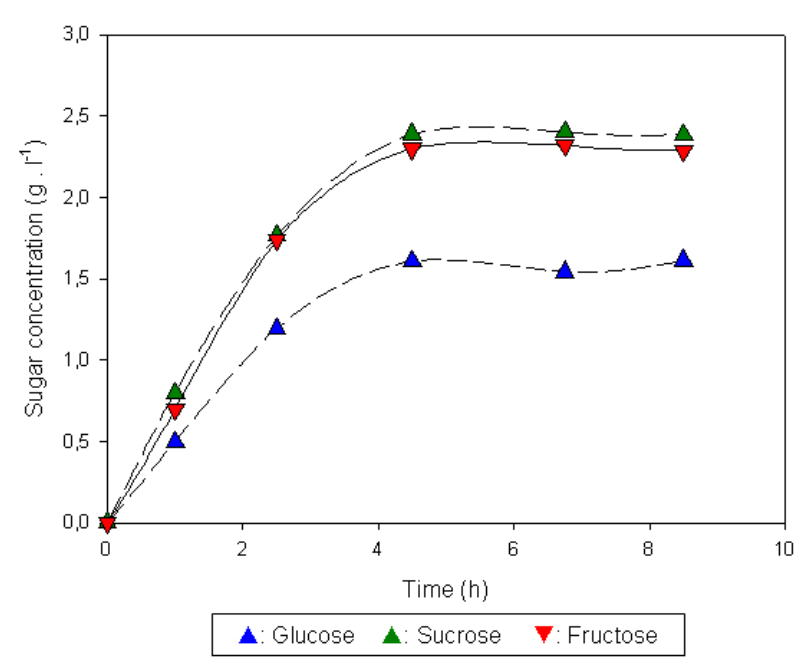

Figure 2. Sugar extraction profile during enzymatic tissue maceration using PPase-SE.

Batch cultures were run in triplicate 500-ml Erlenmeyers flasks containing $50 \mathrm{ml}$ of medium, at $30^{\circ} \mathrm{C}$, on a rotary shaker at $200 \mathrm{rpm}$. The microorganism was also cultivated batchwise in a 4-1 LH 210 bioreactor (Inceltech, France) with 31 of medium, at $30^{\circ} \mathrm{C}$, with aeration $(0.2 \mathrm{vvm})$ and agitation $(500 \mathrm{rpm})$. Outlet gas was analyzed with a paramagnetic $\mathrm{O}_{2}$ detector (Series 1100, Servomex, USA) and an infrared $\mathrm{CO}_{2}$ detector (Pir 2000, Horiba, Japan). RM was used in bioreactor cultures but the component concentrations were doubled except for the CES (glucose). When the culture achieved the stationary phase (glucose concentration $\cong 0$ ), $190 \mathrm{~g}$ of fresh lemon peel (cylinders, $\Phi=5 \mathrm{~mm}$ ) were added and the culture continued until no more growth was detected. This second stage of the culture was carried out under non-aseptic conditions. Culture solids (including biomass and the remaining of lemon tissues) were removed by centrifugation ( $20 \mathrm{~min}, 6,000 \mathrm{x} g$ ) and the supernatant used for soluble sugars (glucose, fructose and sucrose), urea and extracted pectin determinations.

\section{Analytical techniques}

PGase activity of PPase-SE was determined as previously reported (Ferreyra et al. 2002). Growth in Erlenmeyers cultures using different pectin related substances was determined by microscopic observations. The analytical techniques for biomass quantification were the same as described previously (Cavalitto et al. 2000). Cell dry weight could not be determined in the culture with lemon peel because of the presence of solids different from the biomass. In this case, biomass production was indirectly measured from the urea consumption, nitrogen content of the cells and that the general assumption is that nitrogen is not mineralized (Minas et al. 2000). Urea and ammonia were determined with a commercial kit (Uremia Wienner Argentina) and G. klebahnii nitrogen content was measured by semi-micro Kjeldahl method according to the AOAC Norm \# 920.152 (AOAC, 2000).
Soluble sugars (glucose, fructose and sucrose) were determined by High Performance Liquid Chromatography (HPLC). A Waters HPLC modular system equipped with a pump (model 1525), RI detector (model 2414) and a Shodex SC1011 column, was used for analysis. The injection volume was $10 \mu \mathrm{l}$. The samples were eluted with HPLC grade water at a flow rate of $1.0 \mathrm{ml} / \mathrm{min}$ at $85^{\circ} \mathrm{C}$. Glucose, fructose and sucrose in samples were identified and quantified by comparison of their retention times with those of standards (Makino et al. 2000).

Soluble pectin was measured by the classical method developed by Blumenkrantz and Asboe Hansen for determination of uronic acids.

Extracted pectin present in the culture supernatant was precipitated by the addition of 3 vols. of ethanol, at $4^{\circ} \mathrm{C}$, recovered by centrifugation, washed with ethanol and dried at $40^{\circ} \mathrm{C}$. Final yield of enzymatically extracted pectin (dry) was calculated on the basis of the amount of (wet) lemon peel added to the culture. Relative viscosity of the enzymatically extracted pectin $(0.15 \% \mathrm{p} / \mathrm{v})$ solutions, in sodium acetate buffer $(0.2 \mathrm{M}, \mathrm{pH} 5.0)$, was assayed with an Ostwald 100 viscosimeter, at $30^{\circ} \mathrm{C}$.

\section{RESULTS}

Different pectin-related substrates were tested as CES for the growth of G. klebahnii. Results of the cultures carried out in Erlenmeyer flasks with $50 \mathrm{ml}$ of RM using different CES are shown in Table 1. The microorganism showed very poor growth with all pectins tested, even when the cultures were prolonged until $80 \mathrm{hrs}$. In all these cases, the minor growth observed could be associated to the metabolization of contaminating sugars (traces) present in the pectins.

PGA and enzymatically hydrolyzed PGA were also tested as CES, with very poor results. A mixture of galacturonic acid oligomers (di-, tri- and tetra-oligomers) with very small amounts of GALA monomers is obtained as the final product of the reaction of PPase-SE with PGA, as determined by size exclusion chromatography (Sakai, 1992).

Lemon peel extract solution and lemon peel (fresh) supported microbial growth, probably due to the presence of free sugars such as glucose and fructose from the lemon tissue (sucrose is not metabolized by this strain). Washed lemon peel did not support fungal growth, demonstrating that the insoluble materials present in lemon peel are not metabolized by the strain.

In all cultures, final $\mathrm{pH}$ values increased in relation to the initial $\mathrm{pH}(5.0)$, due to ammonia production from urea $(G$. klebahnii is urease + ) without assimilation. The rate of $\mathrm{pH}$ increment after CES exhaustion (data not shown), and also final $\mathrm{pH}$ values, were positively correlated with final biomass levels achieved. In addition, G. klebahnii forms 
short hyphae when it grows in poor media, whereas it shows branched filamentous forms (pseudomycelium) in rich media, as seen in our results.

Some attempts were carried out to determine if G. klebahnii could use pectin as CES when substantial amounts of PPase-SE are already present in the inoculum. For this purpose, the strain was grown in RM and then transferred to different media (based on RM) which were prepared by decreasing the amount of glucose (from 5 to $0 \mathrm{~g} / \mathrm{l}$ ) and increasing the amount of citrus pectin (from 0 to $5 \mathrm{~g} / \mathrm{l}$ ). Biomass content in these cultures could not be easily measured because of pectin interferences, particularly at high concentrations. Therefore, it was indirectly measured from the urea consumption, based on the fact that $G$. klebahnii cells contain $8 \%$ nitrogen, as previously determined. Figure 1 shows the results of this experiment. It is clear that biomass production is proportional to the amount of initial glucose concentration. Pectin was not metabolized in any case, even when G. klebahnii was in active growth when glucose was exhausted.

Enzymatic maceration of lemon peel was carried out in order to determine the capacity of PPase-SE to liberate soluble sugars from the fresh tissue. All sugars (glucose, fructose and sucrose) were released simultaneously, reaching their highest concentrations at $5 \mathrm{hrs}$ of incubation, when the tissue was completely macerated, and then they leveled off (Figure 2).

The capacity of the strain to solubilize pectin from lemon peel, and subsequently utilize the enzymatically extracted lemon peel pectin as CES was assayed. For this purpose, a batch culture was carried out in bioreactor using the RM in which the concentrations of all the components (except glucose) were doubled. The increment of non-glucose components was done in order to support fungal growth during the second stage of the culture (Figure 3 ).

During the first stage of the culture, the microorganism grew well and produced PPase-SE, reaching $15 \mathrm{U} / \mathrm{ml}$. No free ammonia could be detected; therefore urea consumption could be directly correlated with biomass formation. $\mathrm{O}_{2}$ consumption and $\mathrm{CO}_{2}$ production rates achieved maximum values during the exponential growth phase, when enzyme production rate was also maximal. Respiratory quotient $\left(\mathrm{r}_{\mathrm{O} 2} / \mathrm{r}_{\mathrm{CO} 2}\right)$ was approximately 1 as a consequence of a completely aerobic metabolism of the strain without secondary product formation.

After glucose exhaustion, fresh lemon peel was added to the culture. Although this culture stage was carried out under non-aseptic conditions, no microbial contamination was observed. The strain recovered very fast from the short period of CES starvation and no culture lag phase was observed. Soluble sugars released from the lemon peel supported fungal growth, which continued until glucose and fructose were totally consumed. Glucose was metabolized before fructose, and sucrose remained not metabolized. $\mathrm{O}_{2}$ consumption and $\mathrm{CO}_{2}$ production rates achieved maximum values at the beginning of this stage, when the rates of lemon peel maceration and solubilization of sugars and pectin were also maximal. Respiratory quotient $\left(\mathrm{r}_{\mathrm{O} 2} / \mathrm{r}_{\mathrm{CO} 2}\right)$ was approximately 1 .

A typical stoichiometric analysis for microbial growth applied to the two culture stages is shown in Table 2. Total CES liberated from lemon peel during the second stage (glucose plus fructose) was calculated from the data of enzymatic maceration of lemon peel (Figure 2). Biomass yields $\left(y_{\mathrm{X} / \mathrm{S}}\right)$ were very similar for both stages, and close to the typical values for aerobic metabolism of carbohydrates. Although biomass content was indirectly estimated, carbon balances were very close to 1 indicating that glucose and fructose were the only CES used by the microorganism during the second culture stage. From these results it can be concluded that the growth of the strain on lemon peel is supported by the sugars released (glucose and fructose) and no other carbohydrate is metabolized.

During the second culture stage, PPase-SE released pectin from the added lemon peel. The pectin extracted at different cultivation times was characterized according to its relative viscosity. It is remarkable that there is a linear correlation between relative viscosity of pectin solutions and pectin molecular weight, a fundamental parameter to characterize

Table 2. Stoichiometric analysis of the two stages of the G. klebahnii culture corresponding to Figure 3.

\begin{tabular}{|l|c|c|c|c|c|c|c|c|c|}
\hline & $\mathbf{\Delta S}(\mathbf{g} / \mathbf{l})$ & $\mathbf{\Delta X}(\mathbf{g} / \mathbf{l})$ & $\begin{array}{c}\mathbf{O}_{2} \text { tot } \\
(\mathbf{m m o l e} / \mathbf{l})\end{array}$ & $\begin{array}{c}\mathbf{C O}_{2} \text { tot } \\
(\mathbf{m m o l e} / \mathbf{l})\end{array}$ & $\boldsymbol{y}_{\mathbf{x} / \mathbf{s}}$ & $\boldsymbol{y}_{\text {co2/s }}$ & $\mathbf{b}$ & $\mathbf{C B}$ & $\mathbf{B Y}$ \\
\hline First stage & 5.21 & 2.38 & 87.24 & 93.61 & 0.534 & 0.537 & 0.502 & 1.07 & 1.06 \\
\hline Second stage & 4.65 & 2.303 & 57.75 & 57.31 & 0.576 & 0.370 & 0.373 & 0.946 & 0.977 \\
\hline
\end{tabular}

By: Reduction degree balance.

CB: Carbon balance. 


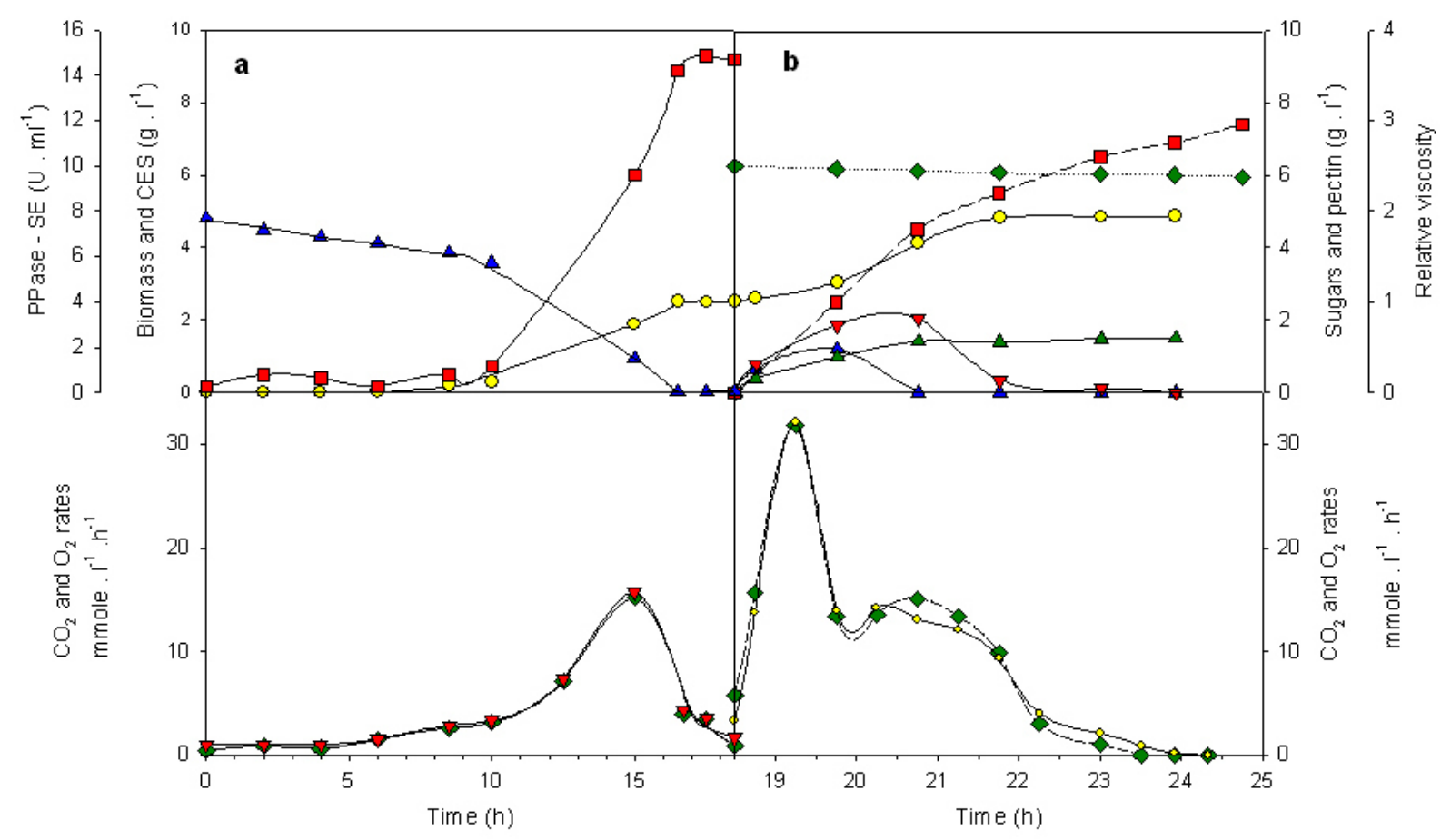

ㅁ: Enzyme activity; : Biomass; $\diamond: \mathrm{O}_{2}$ consumption rate; $\nabla: \mathrm{CO}_{2}$ production rate; $\boldsymbol{\Lambda}$ : Glucose. A: Sucrose; $\nabla$ : Fructose; $\square:$ Extracted pectin; : Relative viscosity of extracted pectin.

Figure 3. Time course of G. klebahnii culture in bioreactor before (a) and after (b) lemon peel addition.

commercial pectins from their practical use. As seen, relative viscosity of extracted pectin showed almost constant values around 2.45. This means that extracted pectin was not degraded during the culture. Macro and microscopic observations demonstrated that lemon peel tissues were completely macerated in $3 \mathrm{hrs}$ of culture. Final yield of pectin extraction was $3.7 \mathrm{~g} / 100 \mathrm{~g}$ of lemon peel, which is an adequate yield for practical purposes.

The lemon pectin enzymatically extracted during the above described batch culture was precipitated from the supernatant and used as CES in Erlenmeyer flasks cultures, as described before, in order to reconfirm the lack of capacity of G. klebahnii to utilize pectin as CES. No growth could be observed even up to $80 \mathrm{hrs}$ of culture, in a similar way as previously mentioned for the cases of pectins of other origins.

\section{DISCUSSION}

The capacity of G. klebahnii to utilize different pectins (commercial or prepared at the laboratory) as CES was tested. It is remarkable that the pectins used have different origins and chemical characteristics (contents of GALA and neutral sugars, methoxylation degree, molecular weight); nevertheless, none of them could be metabolized by the strain.

In addition, oligogalacturonase activity (needed to hydrolyze GALA oligomers) could not be detected in this strain. Therefore, PPase-SE hydrolyzes PGA but only the small amounts of GALA monomers obtained can be metabolized by the strain as previously demonstrated (Cavalitto et al. 2000). PGA (able to be degraded by PPaseSE to obtain GALA monomers) can hardly be found in the natural habitats of the strain. Thus, from this point of view, PPase-SE activity does not contribute to the supply of CES to the strain. Therefore, we concluded that this strain is able to release pectin from lemon peel, but it is unable to metabolize it.

The biological talk between a plant pathogen and its host is a complex interaction of signals and responses. EndoPGases have long been proposed to play an important role in fungal colonization of plant tissues by degrading the homogalacturonan regions of pectin in the plant cell wall (Lang and Dornenburg, 2000). The enzymatic maceration of plant tissues, in which cells are freed from one another, is an important factor in plant pathogenesis (and also in modern Food Technology). This is a process in which protopectin contained in the middle lamella is dissolved, releasing the plant cells and, in the case of using PPases, high molecular weight soluble pectin. Other pectinases macerate plant tissues with simultaneous depolymerization of pectin. PPase-SE is highly efficient for the maceration of different plant tissues, such as potato, but it also can macerate carrot and red pepper tissues. Maceration of plant tissues depends, among other factors, on the specificity of the enzyme to the tissue (Pretel et al. 2005). Here, we 
demonstrate that enzymatic lemon peel maceration with PPase-SE is a simultaneous process to pectin extraction, and that extracted pectin remains non-degraded during extraction.

The plant cell wall is composed of two types of polysaccharide matrices: the pectate network and the cellulose network. A simple but major pathogenic mechanism in plants involves degradation of the cell wall by a battery of polysaccharidases secreted by the pathogens (Herron et al. 2000). This mechanism does not seem to apply to G. klebahnii because only one enzyme activity (PPase-SE) could be detected in culture supernatants (data not shown). Endo-PGases have long been proposed to play an important role in fungal pathogenicity by degrading the homogalacturonan regions of protopectin, a major component of plant cell walls. In addition, research on endo-PGases has been widened by the finding that these proteins are able to elicit plant defence responses through the release of active oligosaccharides and pectic fragments, particularly oligogalacturonides (Boudart et al. 1998).

The function of polygalacturonases in yeasts is largely unknown, and it is remarkable that two different types of yeasts may be discerned. One group includes yeasts that, like filamentous fungi, have the ability to growth using pectic substances as the sole CES, suggesting a complex enzymic system, such as in the cases of Cryptococus albidus and C. boidinii (Blanco et al. 1999).

The other group comprises those yeasts unable to use pectin, pectate or their hydrolysis products as CES (da Silva et al. 2005), and these strains mainly produce endopolygalacturonases able to degrade pectic substrates. This fact challenges the ability to investigate the real physiological role of pectolytic enzymes in these species. As far as it is known, these enzymes could be involved in substrate colonization (fruits). This causes the breakdown of plant tissues with the concomitant release of sugars from plant cells, which in turn can be utilized for yeast growth, hence causing further spoilage (da Silva et al. 2005).

From all of the aforementioned facts, it can be concluded that G. klebahnii seems to be similar to the second group of yeasts. PPase-SE shows an ecological role rather than a trophic one. G. klebahnii seems to use it to macerate and, in this way, to invade plant tissues to get the soluble sugars used as CES without metabolizing solubilized pectin. Nevertheless, a difference exists between the yeasts belonging to the second group and G. klebahnii because in this last case solubilized pectin remains non-degraded. Consequently, the elicitation of plant defence responses by oligogalacturonides does not take place. From this point of view, G. klebahnii shows a differential behaviour compared with other plant pathogens.

\section{REFERENCES}

Association of Official Analytical Chemists International (AOAC International). Official Methods of Analysis. $17^{\text {th }}$ ed. Maryland, AOAC International, 2000. 2200 p. ISBN 0935584-67-6.

BLANCO, Pilar; SIERIO, Carmen and VILLA, Tomás G. Production of pectic enzymes in yeast. FEMS Microbiology Letters, June 1999, vol. 175, no. 1, p. 1-9.

BOUDART, Georges; LAFITTE, Claude; BARTHE, Jean Paul; FRASEZ, Denis and ESQUERRE-TUGAYE, MarieThérèse. Differential elicitation of defense responses by pectic fragments in bean seedlings. Planta, July 1998, vol. 206, no. 1, p. 86-94.

CAVALITTO, Sebastián F.; HOURS, Roque A. and MIGNONE, Carlos F. Growth and protopectinase production of Geotrichum klebahnii in batch and continuous cultures with synthetic media. Journal of Industrial Microbiology and Biotechnology, November 2000, vol. 25, no. 5, p. 260-265.

CAVALITTO, Sebastián F. and MIGNONE, Carlos F. Application of factorial and Doehlert designs for optimization of protopectinase production by a Geotrichum klebahnii strain. Process Biochemistry, February 2007, vol. 42, no. 2, p. 175-179.

CONTRERAS ESQUIVEL, J.C.; HOURS, R.A.; AGUILAR, C.N.; REYES-VEGA, M.L. and ROMERO, J. Revisión: Extracción microbiológica y enzimática de pectina. Archivos Latinoamericanos de Nutrición, September 1997, vol. 47, no. 3, p. 208-216.

DA SILVA, Evânia Geralda; BORGES, Maria de Fátima; MEDINA, Clara; PICCOLI, Roberta Hilsdorf and SCHWAN, Rosane Freitas. Pectinolytic enzymes secreted by yeasts from tropical fruits. FEMS Yeast Research, June 2005 , vol. 5 , no. 9 , p. 859-865.

FERREYRA, Oscar A.; CAVALITTO, Sebastián F.; HOURS, Roque A. and ERTOLA, Rodolfo J. Influence of trace elements on enzyme production: protopectinase expression by a Geotrichum klebahnii strain. Enzyme and Microbial Technology, September 2002, vol. 31, no. 4, p. 498-504.

HERRON, Steven R.; BENEN, Jacques A.E.; SCAVETTA, Robert D.; VISSER, Jaap and JURNAK, Frances. Structure and function of pectic enzymes: Virulence factors of plant pathogens. Proceedings of the National Academy of Sciences of the United States of America, August 2000, vol. 97 , no. 16 , p. 8762-8769.

LANG, C. and DORNENBURG, H. Perspectives in the biological function and the technological application of 
Rojas, N.L. et al.

polygalacturonases. Applied Microbiology and Biotechnology, April 2000, vol. 53, no. 4, p. 366-375.

MAKINO, Yasushi; OMICHI, Kaoru; KURAYA, Nahoki; OGAWA, Hideyuki; NISHIMURA, Hitoshi; IWANAGA, Sadaaki and HASE, Sumihiro. Structural analysis of $N$ Linked sugar chains of human blood clotting factor IX ${ }^{1}$. Journal of Biochemistry, August 2000, vol. 128, no. 2, p. 175-180.

MINAS, Wolfgang; BAILEY, James E. and DUETZ, Wouter. Streptomycetes in micro-cultures: Growth, production of secondary metabolites, and storage and retrieval in the 96-well format. Antonie van Leeuwenhoek International Journal of General and Molecular Microbiology, December 2000, vol. 78, no. 3-4, p. 297-305.

NAKAMURA, Takashi; HOURS, Roque A. and SAKAI, Takuo. Enzymatic maceration of vegetables with protopectinases. Journal of Food Science, May 1995, vol. 60 , no. 3, p. 468-472.

PRETEL, M. Teresa; AMOROS, Asunción; BOTELLA, M. Angeles; SERRANO, María and ROMOJARO, Félix. Study of albedo and carpelar membrane degradation for further application in enzymatic peeling of citrus fruits. Journal of the Science of Food and Agriculture, January 2005, vol. 85, no. 1, p. 86-90.

SAKAI, Takuo and OKUSHIMA, Minoru. Microbial production of pectin from citrus peel. Applied and Environmental Microbiology, April 1980, vol. 39, no. 4, p. 908-912.

SAKAI, Takuo. Degradation of pectins. In: WINKELMANN, G. ed. Microbial degradation of natural products. Weinheim, Germany, VCH Publishers, 1992, p. 57-81. ISBN 3527283544.

VAN ALEBEEK, G.-J.W.M.; ZABOTINA, O.; BELDMAN, G.; SCHOLS, H.A. and VORAGEN, A.G.J. Esterification and glycosydation of oligogalacturonides: examination of the reaction products using MALDI-TOF MS and HPAEC. Carbohydrate Polymers, September 2000, vol. 43, no. 1, p. 39-46. 